\title{
Hydrogen Sulfide Improves the Endothelial Dysfunction in Renovascular Hypertensive Rats
}

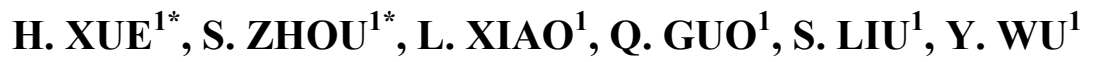 \\ ${ }^{*}$ These authors contributed equally to this work. \\ ${ }^{1}$ Department of Physiology, Hebei Medical University, Shijiazhuang, Hebei, China
}

Received June 12, 2014

Accepted January 16, 2015

On-line March 24, 2015

\begin{abstract}
Summary
As a novel gasotransmitter, hydrogen sulfide $\left(\mathrm{H}_{2} \mathrm{~S}\right)$ has vasodilating and antihypertensive effects in cardiovascular system. Thus, we hypothesized that $\mathrm{H}_{2} \mathrm{~S}$ might have beneficial effects on thoracic endothelial function in two-kidney one-clip (2K1C) rats, a model of renovascular hypertension. Sodium hydrosulfide (NaHS, $56 \mu \mathrm{mol} / \mathrm{kg} /$ day) was administrated intraperitoneally from the third day after the $2 \mathrm{~K} 1 \mathrm{C}$ operation. Along with the development of hypertension, the systolic blood pressure (SBP) was measured before the operation and each week thereafter. The oxidative stress was determined by measurement of malondialdehyde (MDA) concentration, superoxide dismutase (SOD) activity and protein expression of oxidative stress-related proteins ( $A T_{1} R_{1}, N A D P H$ oxidase subunits). Acetylcholine (ACh)-induced vasorelaxation and angiotensin II (Ang II)-induced vasocontraction were performed on isolated thoracic aorta. The SBP was significantly increased from the first week after operation, and was lowered by NaHS. NaHS supplementation ameliorated endothelial dysfunction. The protein expression of oxidative stress-related proteins were downregulated, while SOD activity upregulated. In conclusion, improvement of endothelial function is involved in the antihypertensive mechanism of $\mathrm{H}_{2} \mathrm{~S}$. The protective effect of $\mathrm{H}_{2} \mathrm{~S}$ is attributable to suppression of vascular oxidative stress that involves inhibition of Ang II-AT ${ }_{1} R$ action, downregulation of oxidases, as well as upregulation of antioxidant enzyme.
\end{abstract}

\section{Key words}

Hydrogen sulfide - Angiotensin II • Endothelial dysfunction • Oxidative stress

\section{Corresponding author}

Y. Wu, Department of Physiology, Hebei Medical University,
361 East Zhongshan Road, Shijiazhuang, Hebei 050017, China. Fax: +86-311-86266407. E-mail: wuyum@yahoo.com

\section{Introduction}

The novel gasotransmitter hydrogen sulfide $\left(\mathrm{H}_{2} \mathrm{~S}\right)$ possessed various physiological and pharmacological functions in cardiovascular system (Wang 2002). Nowadays, $\mathrm{H}_{2} \mathrm{~S}$ has been found to be produced by cystathionine $\beta$-synthase (CBS), cystathionine $\gamma$-lyase (CSE) and newly determined 3mercaptopyruvate sulfurtransferase (3-MST) in concert with cysteine aminotransferase (CAT) (Tanizawa 2011). In particular, CSE is the main generating enzyme to be present in vascular bed and additionally located in vascular endothelial cells, which contributes to endothelium-dependent relaxation (Zhao et al. 2001). The vasorelaxing effect of $\mathrm{H}_{2} \mathrm{~S}$ has been appeared in various vascular tissues, such as rat aorta and mesenteric arteries (Wang et al. 2009). Moreover, CSE knockdown increased blood pressure (Yang et al. 2008), which might be eliminated by in vivo administration of $\mathrm{H}_{2} \mathrm{~S}$ (Mancardi et al. 2009). In addition, plasma level of $\mathrm{H}_{2} \mathrm{~S}$ was significantly decreased in spontaneously hypertensive rats (SHRs) (Zhao et al. 2008) and renovascular hypertensive rats (Lu et al. 2010). Thus, we hypothesized that there might be a correlation between $\mathrm{H}_{2} \mathrm{~S}$ and vascular function in hypertensive animal model.

Renovascular hypertension caused by partial renal-artery stenosis always leads to persistent high blood pressure and increased angiotensin II (Ang II) activity (Higashi et al. 2002, Takahashi and Smithies 2004). Ang II, acting via the angiotensin II type 1 receptor 
$\left(\mathrm{AT}_{1} \mathrm{R}\right)$, increases the activity of nicotinamide adenine dinucleotide phosphate (NADPH) oxidase, which was proposed as a mechanism underlying the enhanced production of reactive oxygen species (ROS), especially superoxide anion $\left(\mathrm{O}_{2}{ }^{-}\right)$in a rat model of renovascular hypertension (Oliveira-Sales et al. 2009). The association between increased production of $\mathrm{O}_{2}{ }^{-}$and endothelial dysfunction has been reported in both experimental and human renovascular hypertension (Cai and Harrison 2000, Dijkhorst-Oei et al. 1999, Taddei et al. 1993).

Vasoactive substances released by endothelium play an important role in regulating vascular tone and blood pressure (Bayraktutan 2002). The imbalance between endothelium-derived relaxing and contracting factors leads to endothelial dysfunction, which is related to cardiovascular mortality (Vanhoutte et al. 2009). In a large amount of experimental hypertensive models, such as two-kidney, one-clip (2K1C) renovascular, aortic coarctation, Dahl salt-sensitive, deoxycorticosterone acetate-salt and SHRs, the endothelium-dependent vasorelaxation is severely impaired (Choi et al. 2012). $\mathrm{H}_{2} \mathrm{~S}$ has been reported to be produced from vascular endothelial cells and be considered as a newly endothelial-dependent relaxing factor (EDRF) or endothelial-dependent hyperpolarized factor (EDHF), which plays a pivotal role in regulating endothelial function (Wang 2009). However, no studies show that $\mathrm{H}_{2} \mathrm{~S}$ could improve endothelial dysfunction in $2 \mathrm{~K} 1 \mathrm{C}$ model.

Sodium hydrosulfide (NaHS) is an $\mathrm{H}_{2} \mathrm{~S}$ donor. Although previous studies reported the antihypertensive effect of this compound (Ahmad et al. 2014, Ford et al. 2013), the effects of NaHS on vascular function in renovascular hypertension remain poorly understood. In this study, we investigated the effect of NaHS on endothelial function in chronic $2 \mathrm{~K} 1 \mathrm{C}$ hypertensive rats, which is an ideal animal model of renovascular hypertension, with further elucidation of the underlying mechanisms by focusing on vascular oxidative stress.

\section{Methods}

\section{Animals}

All the rats used in present study were obtained from our local certified animal facility (Animal Research Center of Hebei Medical University, Hebei, China). 7-week old male Sprague-Dawley rats were randomly divided into 3 groups $(\mathrm{n}=6)$ : Sham, $2 \mathrm{~K} 1 \mathrm{C}, 2 \mathrm{~K} 1 \mathrm{C}+\mathrm{NaHS}$. The rats were anesthetized with intraperitoneal injections of pentobarbital sodium $(30 \mathrm{mg} / \mathrm{kg})$. In the $2 \mathrm{~K} 1 \mathrm{C}$ and $2 \mathrm{~K} 1 \mathrm{C}+\mathrm{NaHS}$ groups, a lumbar incision was made to provide access to the left renal artery. Cleared of the connective tissues, the left renal artery was clipped by a rigid U-shaped solid silver clip with an open slit of $0.25 \mathrm{~mm}$, resulting in partial occlusion of renal perfusion. The contralateral kidney was left untouched. Sham group underwent the same procedure, except for the clip placement. The rats were kept in cages after surgery, maintained on $12 \mathrm{~h} \mathrm{light/dark} \mathrm{cycle} \mathrm{with} \mathrm{free} \mathrm{access} \mathrm{to}$ normal chow and tap water. $2 \mathrm{~K} 1 \mathrm{C}+\mathrm{NaHS}$ group received NaHS $56 \mu \mathrm{mol} / \mathrm{kg} /$ day intraperitoneally. The treatment was started from the third day after the surgery and maintained for 4 weeks. Sham and 2K1C groups were received saline as vehicle.

\section{Blood pressure measurement}

Systolic blood pressure (SBP) was measured non-invasively by tail-cuff plethysmography (Chengdu Instrument Factory, Sichuan, China) in calm, conscious rats. Briefly, SBP was measured before and further at each week after surgery for 4 weeks. SBP measurement was always conducted between 9:00 and 12:00 AM and was calculated as the average value of 3 to 4 successive measurement.

\section{Isometric force studies}

The thoracic aorta was dissected, cleaned of connective tissue and cut into ring segments $(-3 \mathrm{~mm}$ length). The segments were then mounted between stainless steel triangles in a $10 \mathrm{ml}$ organ bath filled with oxygenated $\left(95 \% \mathrm{O}_{2}\right.$ and $\left.5 \% \mathrm{CO}_{2}\right)$ Krebs-Henseleit solution ( $\mathrm{pH}$ 7.3-7.5) (composition in $\mathrm{mmol} / \mathrm{l}: \mathrm{NaCl} 119$, $\mathrm{KCl}$ 4.7, $\mathrm{CaCl}_{2} 2.5, \mathrm{MgCl}_{2} 1, \mathrm{NaHCO}_{3} 25, \mathrm{KH}_{2} \mathrm{PO}_{4} 1.2$, glucose 11) at $37^{\circ} \mathrm{C}$. An optional baseline tone of $2 \mathrm{~g}$ was applied to all rings as a resting tension. After a $60 \mathrm{~min}$ equilibration, arteries were stimulated by $60 \mathrm{mmol} / 1 \mathrm{KCl}$. After washing out, rings were precontracted by phenylephrine (Phe, $1 \mu \mathrm{mol} / \mathrm{l})$. When the contraction was steady, acetylcholine (ACh, $10^{-8} \sim 10^{-4}$ $\mathrm{mol} / \mathrm{l}$ ) or sodium nitroprusside (SNP, $10^{-9} \sim 10^{-6} \mathrm{~mol} / \mathrm{l}$ ) were added respectively in a cumulative manner to record the endothelial-dependent relaxation or endothelialindependent relaxation response curve. Ang II $\left(10^{-10} \sim 10^{-6} \mathrm{~mol} / \mathrm{l}\right)$ was added cumulatively to conduct contraction curve. Further, $\mathrm{AT}_{1} \mathrm{R}$ inhibitor losartan $(10 \mu \mathrm{mol} / \mathrm{l})$ was applied for $30 \mathrm{~min}$ before the Ang IIinduced contraction was performed.

The extent of relaxation was expressed as 
percentage of relaxation from a submaximal phenylephrine-induced constriction. Vasocontraction was determined in relative values as the percentage of $60 \mathrm{mmol} / 1 \mathrm{KCl}$ contraction.

\section{Measurement of plasma $\mathrm{H}_{2} \mathrm{~S}$ level}

$\mathrm{H}_{2} \mathrm{~S}$ concentration in plasma was measured as previous described (Siegel 1965). Briefly, plasma $(100 \mu \mathrm{l})$ was mixed with potassium phosphate buffer $(\mathrm{pH} 7.4,2.5 \mathrm{ml})$ and zinc acetate $(1 \% \mathrm{w} / \mathrm{v}, 500 \mu \mathrm{l})$, then further incubated with $N, N$-dimethyl- $p$-phenylenediamine sulfate $(20 \mathrm{mmol} / 1,500 \mu \mathrm{l})$ in $7.2 \mathrm{~mol} / 1 \mathrm{HCl}$ and $\mathrm{FeCl}_{3}$ $(30 \mathrm{mmol} / \mathrm{l}, 400 \mu \mathrm{l})$ in $1.2 \mathrm{~mol} / \mathrm{l} \mathrm{HCl} .10 \%$ trichloroacetic acid $1 \mathrm{ml}$ was added to terminate the reaction after 20-min incubation. The absorbance of the mixture was measured at $665 \mathrm{~nm} . \mathrm{H}_{2} \mathrm{~S}$ concentration was calculated against a calibration curve of NaHS (0.01 to $100 \mu \mathrm{mol} / 1)$. The results of $\mathrm{H}_{2} \mathrm{~S}$ concentration was expressed as $\mu \mathrm{mol} / 1$.

\section{Measurement of plasma Ang II level}

Ang II level in plasma was examined with an Ang II radioimmunoassay kit (Beijing Chemclin Biotech Co. Ltd, Beijing, China). Briefly, blood samples were collected in tubes containing $20 \mu \mathrm{l}$ EDTA in ice. After centrifugation at $1000 \times \mathrm{g}$ for $15 \mathrm{~min}$ at $4{ }^{\circ} \mathrm{C}$, plasma $(1 \mathrm{ml})$ was collected and mixed with enzyme inhibitor 1 (10 $\mu \mathrm{l})$, enzyme inhibitor $2(20 \mu \mathrm{l})$ following the instruction of the radioimmunoassay kit. Then aliquots $(100 \mu \mathrm{l})$ were incubated with ${ }^{125}$ I-AII $(100 \mu \mathrm{l})$ and AII antibody $(100 \mu \mathrm{l})$ for $15 \mathrm{~h}$ at $2-8^{\circ} \mathrm{C}$, followed by addition of separating reagent (including donkey anti-rabbit $\mathrm{IgG}$ serum and polyethylene glycol) $500 \mu$ land incubated for $15 \mathrm{~min}$ at room temperature. The supernatant was discarded after centrifugation at 3,500 r/min for $20 \mathrm{~min}$. The radioactive count was determined for $60 \mathrm{~s}$. The results were expressed as $\mathrm{pg} / \mathrm{ml}$.

\section{Western blot analysis}

Thoracic aorta were homogenized with ice-cold RIPA lysing buffer and centrifuged at $20,000 \times \mathrm{g}$ for $20 \mathrm{~min}$. The supernatant was collected and analyzed for protein concentration using the bicinchoninic acid (BCA) method (Generay Biotechnology, Shanghai, China). Aliquots (100 $\mu \mathrm{g}$ protein) were suspended in six volumes of sample buffer with $5 \% \quad \beta$-mercaptoethanol and denatured at $99{ }^{\circ} \mathrm{C}$ for $10 \mathrm{~min}$. The protein samples were electrophoresed through $10 \%$ SDS-polyacrylamide gel and then transferred onto an immobilon-P polyvinylidene difluoride membrane using wet transfer at $100 \mathrm{~V}$ for $90 \mathrm{~min}$ at $4{ }^{\circ} \mathrm{C}$. The membrane was blocked with $0.05 \%$ Tween-20 Tris-buffered saline (TBST) containing $5 \%$ non-fat milk for $60 \mathrm{~min}$ at room temperature. The blots were then incubated overnight at $4{ }^{\circ} \mathrm{C}$ with anti-AT ${ }_{1} \mathrm{R}$ (1:800, Abcam, Hongkong), anti-Nox2 (1:1000, Abcam, Hongkong), anti-Nox4 (1:1000, Proteintech, Chicago, USA), anti-p6 $7^{\text {phox }}(1: 1000$, EPITOMICS, California, USA) and anti- superoxide dismutase (SOD)-1 (1:1000, Proteintech, Chicago, USA) antibodies. All washes were performed in TBST. The membranes were then incubated with a horseradish peroxidase (HRP)-conjugated goat anti-rabbit antibody (1:2000, Proteintech, Chicago, USA) or HRP-conjugated rabbit anti-goat antibody (1:2000, Proteintech, Chicago, USA) for $1 \mathrm{~h}$. Blots were developed with an enhanced chemiluminescence detection system (Sagecreation, Beijing, China). Densitometry was performed using lane-1 system (Sagecreation, Beijing, China).

\section{Measurement of malondialdehyde (MDA) concentration}

MDA concentration in aorta was measured by using thiobarbituric acid reactive substances (TBARS) assay kit (Nanjing Jiancheng Bioengineering Institute, Nanjing, Jiangsu, China) as previously described (Costa et al. 2009). Thoracic aorta was dissected out and snapped frozen at $-80{ }^{\circ} \mathrm{C}$, then homogenized on ice and centrifuged at $10,000 \times \mathrm{g}$ for $5 \mathrm{~min}$ to collect the supernatant. The supernatant was mixed with $10 \%$ trichloroacetic acid $1 \mathrm{ml}$ and $0.67 \%$ thiobarbituric acid $1 \mathrm{ml}$, followed by 30 -min incubation in a boiling water bath. The absorbance of the mixture (532 nm) was measured. The results were expressed as $\mathrm{nmol} / \mathrm{mg}$ protein.

\section{Measurement of SOD activity}

A SOD immunoassay kit was used to determine the total SOD activity in thoracic rings (Nanjing Jiancheng Bioengineering Institute, Nanjing, Jiangsu, China). Thoracic aorta was perfused with PBS to remove any red blood cells and homogenized on ice. The tissue lysate was centrifuged at $10,000 \times \mathrm{g}$ for $5 \mathrm{~min}$. The supernatant contains total SOD was then incubated with working solution for $20 \mathrm{~min}$ at $37^{\circ} \mathrm{C}$. Read the absorbance at $450 \mathrm{~nm}$ using a microplate reader. The results were expressed as $\mathrm{U} / \mathrm{mg}$ protein.

Drugs

NaHS, Ang II, ACh, SNP were obtained from 
Sigma (Vienna, Austria). Losartan was obtained from ALEXIS (Switzerland). Phe was obtained from TCI (Japan). NaHS was freshly prepared and used to generate $\mathrm{H}_{2} \mathrm{~S}$ in solution according to previous paper ( $\mathrm{Qu}$ et al. 2006).

\section{Statistical analysis}

Data were expressed as the mean $\pm \mathrm{SEM}$. The results were evaluated either by $t$ test or 2-way ANOVA using Graphpad Prism. $\mathrm{p}<0.05$ was considered significant. The dose response curves were analyzed by 2-way ANOVA, followed by vertical contrast with Bonferroni adjustment.

\section{Results}

Effect of NaHS on plasma $\mathrm{H}_{2} \mathrm{~S}$, Ang II level and hypertension in $2 \mathrm{KlC}$ rats

The plasma $\mathrm{H}_{2} \mathrm{~S}$ level in $2 \mathrm{~K} 1 \mathrm{C}$ rats $(26.8 \pm 4.8$ $\mu \mathrm{mol} / \mathrm{l})$ was significantly lower than that in sham rats $(50.6 \pm 6.9 \mu \mathrm{mol} / \mathrm{l}, \mathrm{p}<0.05) .4$ weeks of NaHS treatment elevated the plasma $\mathrm{H}_{2} \mathrm{~S}$ level to $56.4 \pm 9.2 \mu \mathrm{mol} / \mathrm{l}$ $(\mathrm{p}<0.05$, Fig. 1A). However, Compared with sham rats, the plasma Ang II level was significantly higher in $2 \mathrm{~K} 1 \mathrm{C}$ rats $(140.2 \pm 4.7 \mathrm{pg} / \mathrm{ml}$ vs. $101.1 \pm 1.9 \mathrm{pg} / \mathrm{ml}, \mathrm{p}<0.01)$. Treatment with NaHS for 4 weeks lowered the Ang II level to $111.5 \pm 3.4 \mathrm{pg} / \mathrm{ml}$ (Fig. 1B).
A

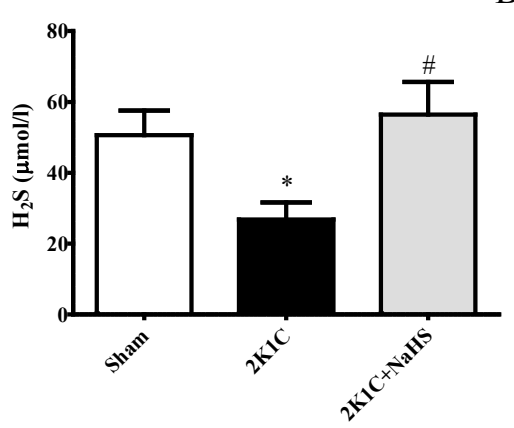

C

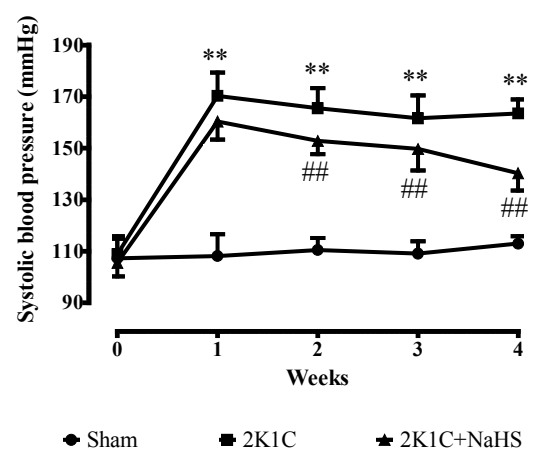

SBP was measured before and weekly after 2K1C surgery. No differences were observed in SBP among the groups before surgery. At the end of the first week, the SBP in $2 \mathrm{~K} 1 \mathrm{C}$ rats was increased from $105.0 \pm 1.2 \mathrm{~mm} \mathrm{Hg}$ to $170.0 \pm 4.0 \mathrm{~mm} \mathrm{Hg}$, and remained elevated throughout the 4-week study period. Sham operation did not affect SBP. Intraperitoneally administrated with NaHS $56 \mu \mathrm{mol} / \mathrm{kg} / \mathrm{day}$ from the third day after surgery reduced the elevation of SBP (Fig. 1C) at the second week after surgery and remained lower than that of the non-treated $2 \mathrm{~K} 1 \mathrm{C}$ rats during the rest of the study period.
Fig. 1. Administration of NaHS for 4 weeks increased the plasma $\mathrm{H}_{2} \mathrm{~S}$ level $(\mathbf{A})$, reduced the plasma Ang II level (B), and attenuated the development of hypertension (C) in $2 \mathrm{~K} 1 \mathrm{C}$ rats. Results are expressed as mean \pm SEM. $n=6, \quad * p<0.05$, $* * \mathrm{p}<0.01$ vs. Sham; ${ }^{\# \#} \mathrm{p}<0.01$ vs. $2 \mathrm{~K} 1 \mathrm{C}$

\section{Effect of NaHS on Ang II-induced vasocontraction}

The Ang II-induced vasocontraction was enhanced in the thoracic aorta of $2 \mathrm{~K} 1 \mathrm{C}$ rats. Such enhancement of vasocontraction was suppressed by the 4-week treatment of NaHS (Fig. 2A,B). In all the three groups including sham and $2 \mathrm{~K} 1 \mathrm{C}$ without or with NaHS treatment, the vasocontraction induced by Ang II was almost abolished by a 30-min preincubation of the aorta with the losartan $(10 \mu \mathrm{mol} / \mathrm{l})$ (Fig. 2C).

Effect of NaHS on endothelium-dependent andindependent vasorelaxation

ACh-induced vasorelaxation was significantly 
reduced in Phe-precontracted aorta in $2 \mathrm{~K} 1 \mathrm{C}$ rats $\left(\mathrm{E}_{\max } 50.8 \pm 3.7 \%\right.$ vs. $100.2 \pm 0.3 \%$ in sham rats, $\left.\mathrm{p}<0.05\right)$. Treatment with NaHS for 4 weeks improved AChinduced endothelium-dependent relaxation $(64.8 \pm 9.4 \%$,
Fig. 3A,B). By contrast, the SNP-induced endothelium independent relaxation showed no differences among sham, 2K1C, and NaHS-treated 2K1C rats. (Fig. 3C,D).
A

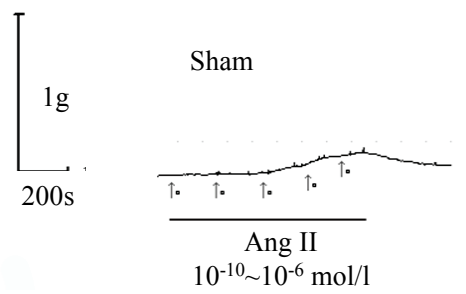

2K1C

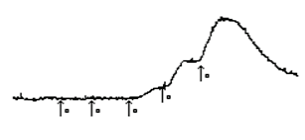

C

B
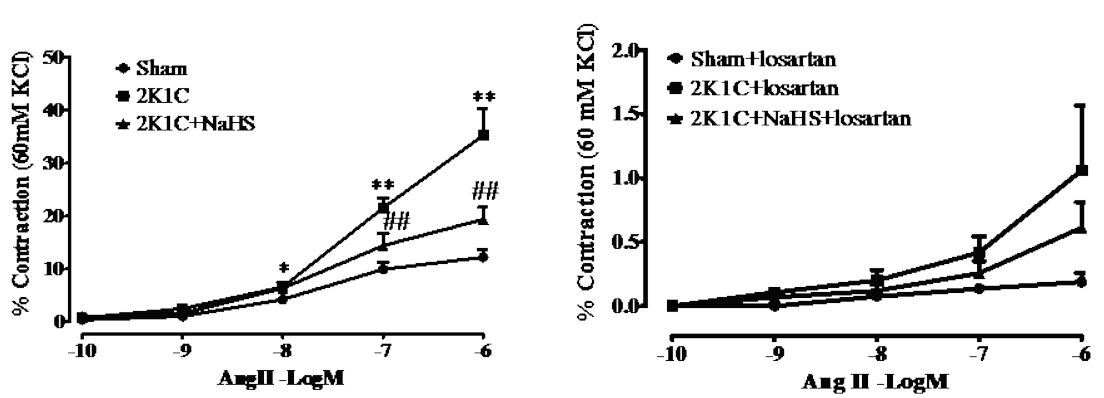

A

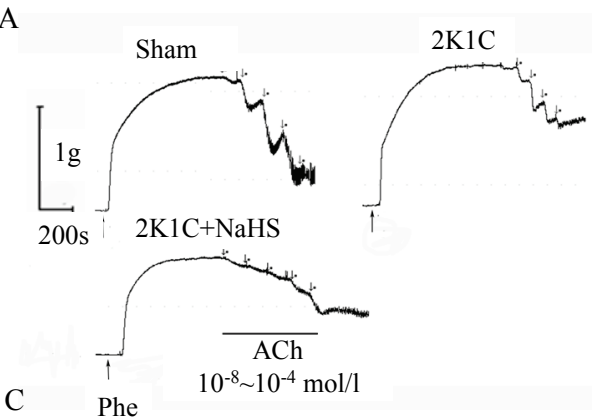

B

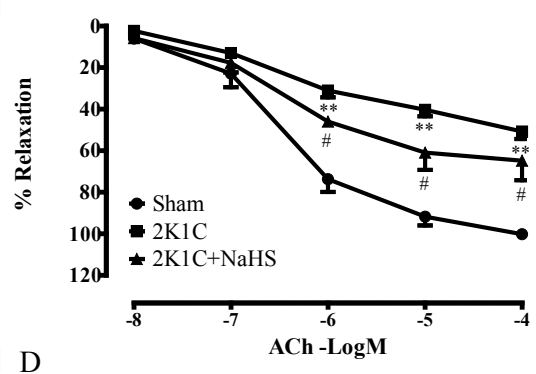

D

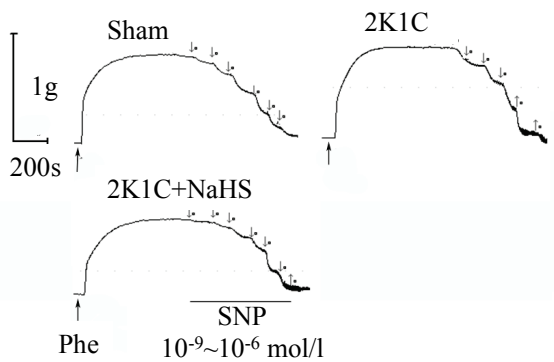

$2 \mathrm{~K} 1 \mathrm{C}+\mathrm{NaHS}$

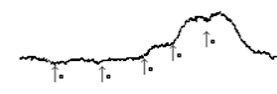
(C). Results are expressed as mean \pm SEM. $\mathrm{n}=6, \quad * \mathrm{p}<0.05$ ** $p<0.01$ vs. Sham; \#\# $p<0.01$ vs. $2 \mathrm{~K} 1 \mathrm{C}$ vasocontraction in rat thoracic aorta

Fig. 2. The Ang II-induced contraction was attenuated by NaHS chronic treatment. NaHS chronic treatment ameliorated the contraction to Ang II (A, B). Pretreatment with losartan $(10 \mu \mathrm{mol} / \mathrm{l})$ for 30 min almost eliminated the Ang II-induced 
A B
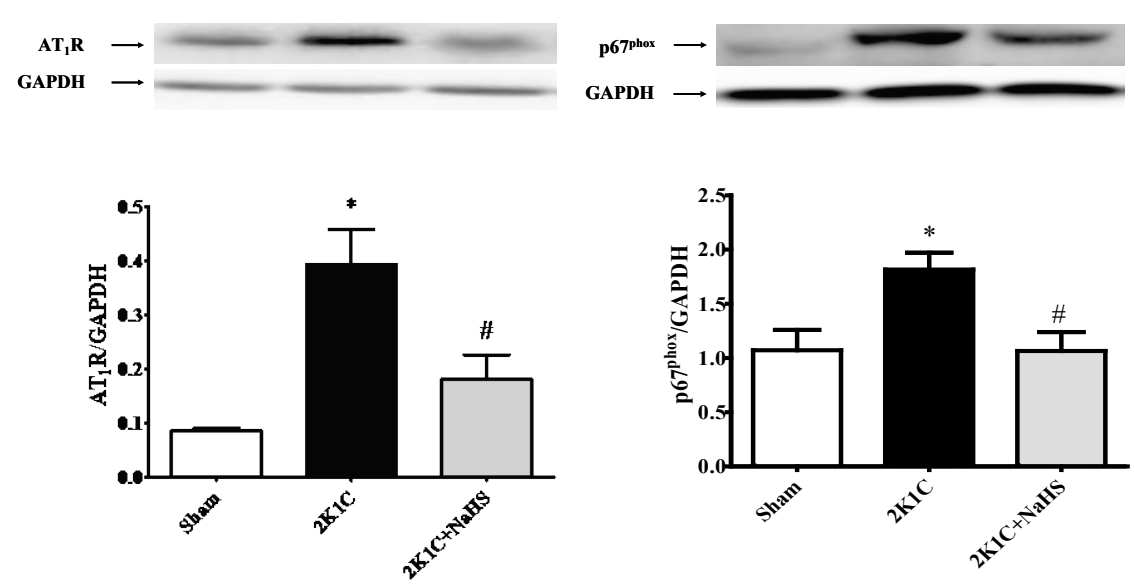

$\mathrm{C}$
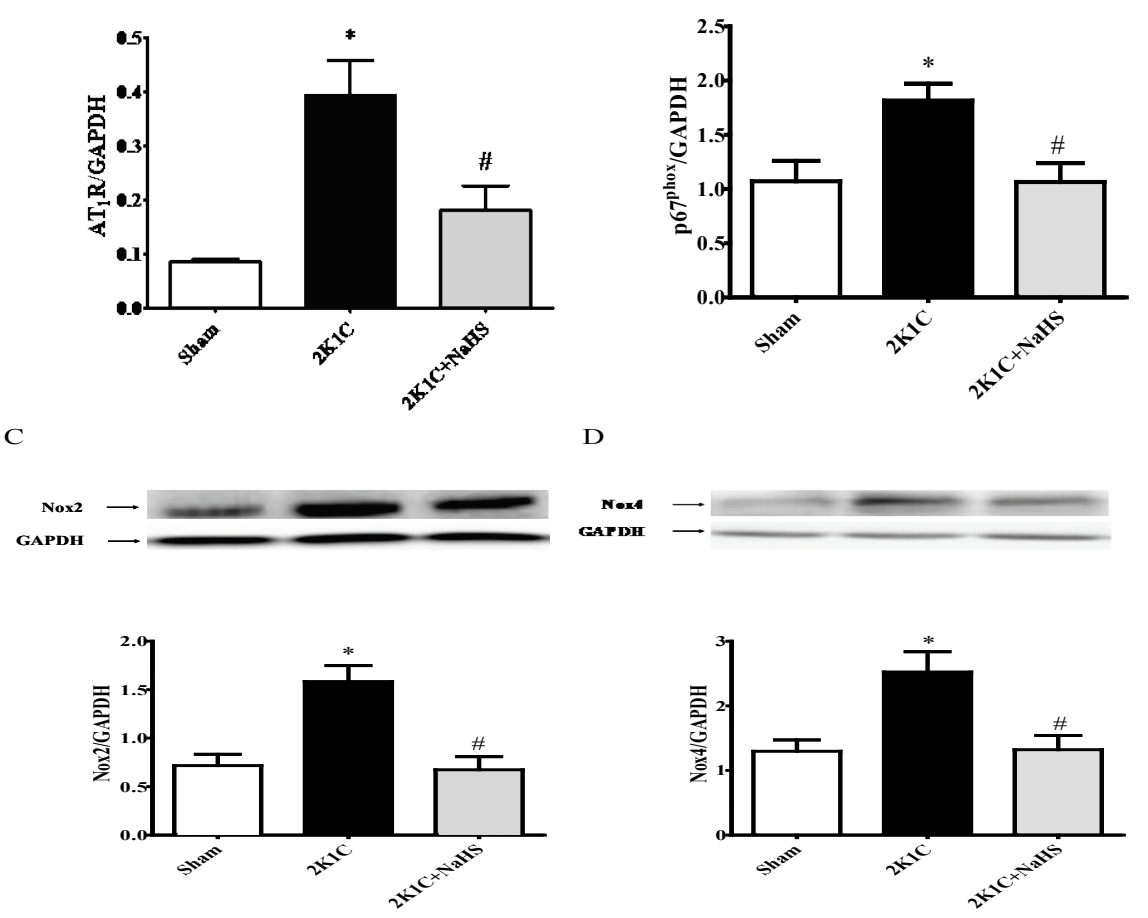

D
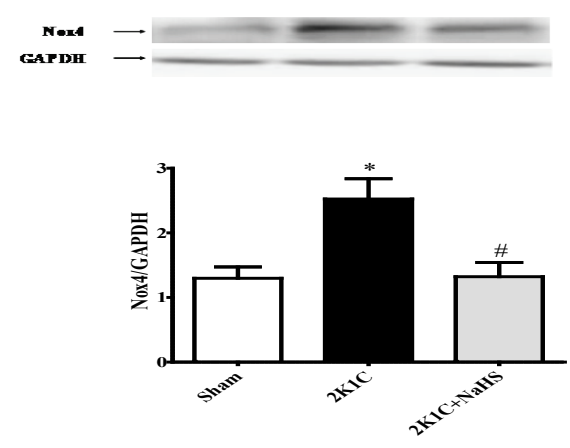

Fig. 4. NaHS chronic treatment reduces the exaggerated protein expression of $\mathrm{AT}_{1} \mathrm{R}(\mathbf{A}), \mathrm{p} 67^{\text {phox }}(\mathbf{B})$, Nox2 (C) and Nox4 (D) in thoracic aorta of 2K1C rats. Results are expressed as mean \pm SEM. $n=4$ or 5 , $* \mathrm{p}<0.05$ vs. Sham; ${ }^{\#} \mathrm{p}<0.05$ vs. $2 \mathrm{~K} 1 \mathrm{C}$

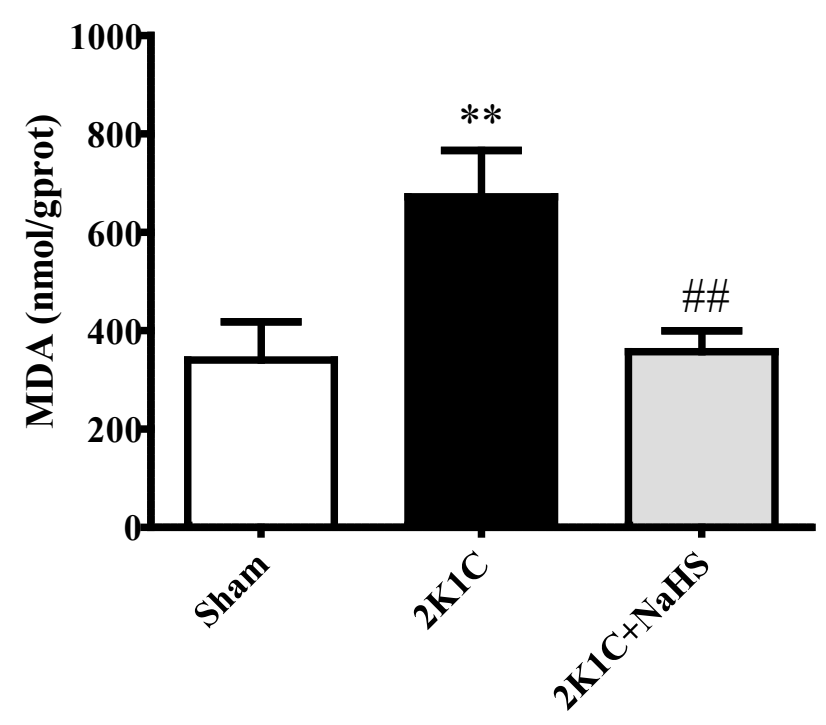

Fig. 5. The MDA level in thoracic aorta was reduced by NaHS 4-week treatment. Results are expressed as mean \pm SEM. $n=6$, ** $p<0.01$ vs. Sham; ${ }^{\# \# ~} \mathrm{p}<0.01$ vs. $2 \mathrm{~K} 1 \mathrm{C}$

\section{Effect of NaHS on SOD}

The tissue SOD activity in rat thoracic aorta was markedly decreased, whereas NaHS chronic treatment reversed the decreased SOD activity in $2 \mathrm{~K} 1 \mathrm{C}$ rats (Fig. 6A). The downregulated protein expression of
SOD-1 was normalized by NaHS supplementation as well (Fig. 6B).

\section{Discussion}

The major findings of this study include: (1) NaHS reduces SBP in 2K1C hypertensive rats; (2) NaHS improves the endothelium-dependent relaxation and suppresses Ang II-induced contraction; (3) this study is the first time to show that $\mathrm{H}_{2} \mathrm{~S}$ downregulates $\mathrm{AT}_{1} \mathrm{R}$ protein expression and oxidative stress in $2 \mathrm{~K} 1 \mathrm{C}$ hypertension. Taken together, the results suggest that $\mathrm{H}_{2} \mathrm{~S}$ protect endothelial function by decreasing oxidative stress in $2 \mathrm{~K} 1 \mathrm{C}$ rats. Figure 7 is a signal transduction diagram depicting the possible mechanisms and assumed pathways.

Previous studies have demonstrated that endothelial function is impaired in $2 \mathrm{~K} 1 \mathrm{C}$ hypertensive rats (Callera et al. 2000) and NaHS exhibits antihypertensive effect in this animal model (Lu et al. 2010), however, the effect of NaHS on endothelial function in renovascular hypertension remains poorly studied. In this study, we demonstrated that NaHS treatment lowered blood pressure in $2 \mathrm{~K} 1 \mathrm{C}$ hypertensive rats, which is 
consistent to previous reports. Improvement of endothelium-dependent relaxation is a mechanism underlying the antihypertensive effect of NaHS. Suppression of vascular responsiveness to Ang II is also involved, evidenced by the attenuated contractile response of aorta to Ang II in rats treated with NaHS that is attributable to the lowered plasma level of Ang II and the downregulation of $\mathrm{AT}_{1} \mathrm{R}$ in vascular cells.

A

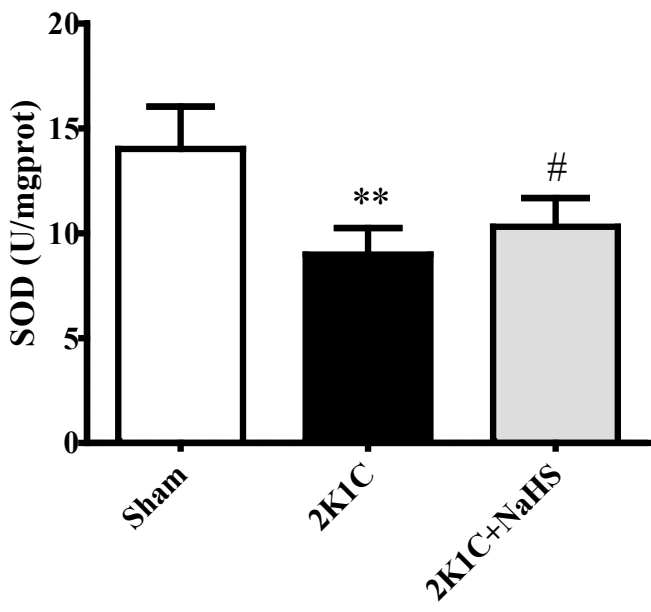

B
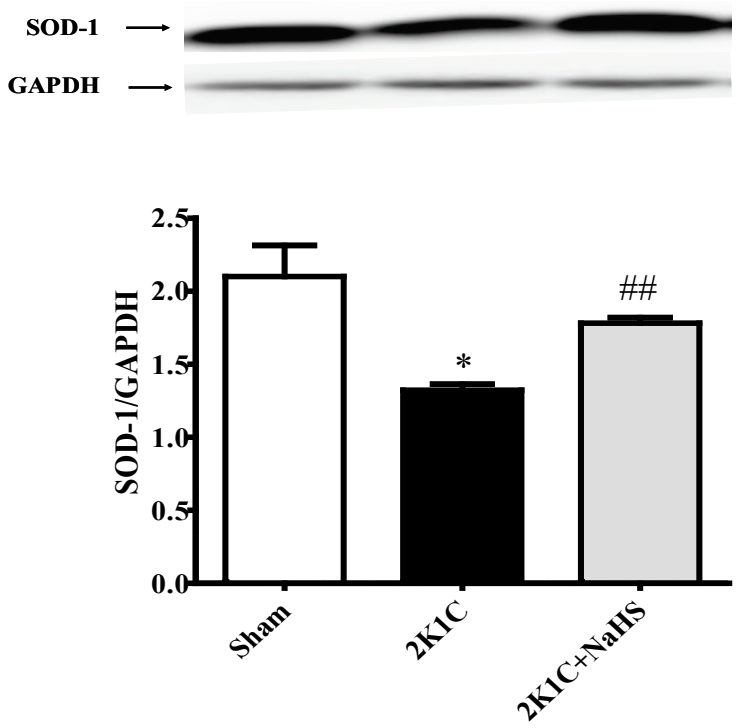

Fig. 6. Treatment with NaHS for 4 weeks remarkably enhanced the tissue activity of SOD (A) and protein expression (B) of SOD-1. Results are expressed as mean \pm SEM. $n=4$ or 5 , ${ }^{*} \mathrm{p}<0.05,{ }^{*} * \mathrm{p}<0.01$ vs. Sham; ${ }^{\#} \mathrm{p}<0.05,{ }^{\# \#} \mathrm{p}<0.01$ vs. $2 \mathrm{~K} 1 \mathrm{C}$

The association between blood pressure elevation and vascular oxidative stress has been extensively reported in the development of hypertension, including essential, renovascular or malignant hypertension (Schulz et al. 2011). As a major source of ROS in vascular cells, NADPH oxidase can be activated by Ang II through acting on $\mathrm{AT}_{1} \mathrm{R}$ (Drummond et al.
2011). Our results showed that NaHS treatment lowered plasma level of Ang II and downregulated aortic $\mathrm{AT}_{1} \mathrm{R}$ protein expression in $2 \mathrm{~K} 1 \mathrm{C}$ hypertensive rats. As a consequence, the inhibition of Ang II-AT $\mathrm{A}_{1} \mathrm{R}$ action likely contributes to the inhibition of NADPH oxidases and the reduction of ROS production.

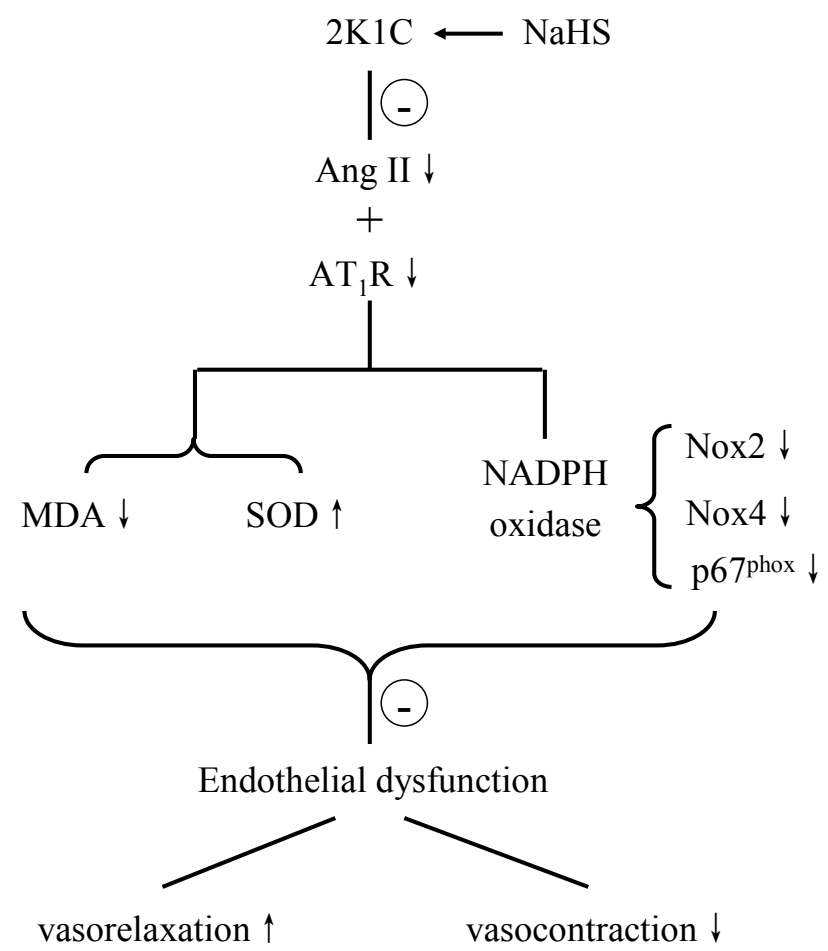

Fig. 7. Schematic diagram of mechanisms underlying the effect of NaHS against endothelial dysfunction in $2 \mathrm{~K} 1 \mathrm{C}$ rats. NaHS prevents endothelial dysfunction in thoracic aorta by inhibition of Ang II-AT $R$ action and downregulation of NADPH oxidases, as well as upregulation of SOD.

Nox proteins represent the catalytic subunits of NADPH oxidase. In various animal models of hypertension including Ang II infusion, deoxycorticosterone acetate-salt, and renovascular hypertension as well as SHRs, increased activity of Nox has been observed (Schulz et al. 2011). Ang II was reported to increase expression of several NADPH oxidase subunits, including Nox1 and Nox4 (Seshiah et al. 2002). In this study, we determined the expression of Nox 2 and Nox4, the most important Nox isoforms in vascular cells (Brown and Griendling 2009), and found that in $2 \mathrm{~K} 1 \mathrm{C}$ rats, protein expressions of Nox 2 and Nox 4 were significantly increased in the aortic tissue. 4-week treatment with NaHS normalized the expression of Nox2 and Nox4. NaHS treatment also lowered the protein level of $\mathrm{p} 67^{\text {phox }}$, the regulatory cytosolic subunit of NADPH, in the aorta of $2 \mathrm{~K} 1 \mathrm{C}$ rats. These results suggested the direct 
inhibitory effect of $\mathrm{H}_{2} \mathrm{~S}$ on NADPH oxidases. Furthermore, we showed that in NaHS-treated animals, the activity of the major antioxidant enzyme SOD is enhanced, accompanied by an upregulation of SOD-1 protein. Taken together, our results demonstrated the potent antioxidant effect of $\mathrm{H}_{2} \mathrm{~S}$ on vascular cells in renovascular hypertensive rats. The inhibition of vascular oxidative stress conferred by $\mathrm{H}_{2} \mathrm{~S}$ was further evidenced by the decreased MDA level in the aortic tissue.

NaHS is commonly used to deliver $\mathrm{H}_{2} \mathrm{~S}$ and increases $\mathrm{H}_{2} \mathrm{~S}$ concentrations rapidly (Li et al. 2008). NaHS incompletely dissociates into $\mathrm{H}_{2} \mathrm{~S}$ in Krebs solution, resulting in about $15-18.5 \%$ being present as $\mathrm{H}_{2} \mathrm{~S}$, with $81.5-85 \%$ existing as hydrosulfide, $\mathrm{HS}^{-}$and a trace of sulfide anion, $\mathrm{S}^{2-}$ (Dombkowski et al. 2004). Which form of $\mathrm{H}_{2} \mathrm{~S}\left(\mathrm{H}_{2} \mathrm{~S}, \mathrm{HS}^{-}\right.$, or $\left.\mathrm{S}^{2-}\right)$ is physiologically active, or whether all three forms are active to varying extents are not known, however the active component is commonly termed as the chemical symbol " $\mathrm{H}_{2} \mathrm{~S}$ " (Al-Magableh et al. 2014). The physiological concentration of $\mathrm{H}_{2} \mathrm{~S}$ is difficult to measure and the measurement of $\mathrm{H}_{2} \mathrm{~S}$ not always gives the consistent values, varying from the previous micromolar range to the recent nanomolar range. Current literature reports several $\mathrm{H}_{2} \mathrm{~S}$ measurement methods, such as spectrophotometry, chromatography, ion-selective electrode and nanoparticles. The methylene blue method used in present study is the most common assay for detecting $\mathrm{H}_{2} \mathrm{~S}$. This method revealed that human and rat serum contains $50-100 \mu \mathrm{M} \mathrm{H} \mathrm{H}_{2} \mathrm{~S}$, which is in consistent with our results. However, this technique detects not only free $\mathrm{H}_{2} \mathrm{~S}$ but also other species such as $\mathrm{HS}^{-}$and $\mathrm{S}^{2-}$, the true plasma concentration of $\mathrm{H}_{2} \mathrm{~S}$ is probably to be lower than tens of micromolar range. Although the methylene method has limitation, the present result is able to indicate that $\mathrm{NaHS}$ treatment increased $\mathrm{H}_{2} \mathrm{~S}$ concentration in $2 \mathrm{~K} 1 \mathrm{C}$ rats.

Previous studies showed that NaHS $>50-100 \mu \mathrm{M}$ is required to relax blood vessels in organ bath, $10-50 \mu \mathrm{mol} / \mathrm{kg}$ are needed to bring about significant falls in blood pressure. NaHS ( $56 \mu \mathrm{mol} / \mathrm{kg} /$ day, i.p.) treatment for 4 to 5 weeks decreased blood pressure and oxidative stress, inhibited atherogenesis and reduced atherosclerotic lesion size (Chen et al. 2011, Wang et al. 2009, Yan et al. 2004). Although lower doses of NaHS treatment (e.g. 10 or $30 \mu \mathrm{mol} / \mathrm{kg} / \mathrm{day}$, i.p.) were also effective in reducing blood pressure, a much longer treatment period (3 months) would be needed. Also, treatment with different doses of NaHS (10, 30 and $90 \mu \mathrm{mol} / \mathrm{kg} /$ day) in SHRs showed no obvious dose-related difference in blood pressure reduction (Shi et al. 2007). The present study showed the beneficial effect of NaHS in lowering blood pressure, improving endothelial function, reducing vascular superoxide production were all observed at a dose of $56 \mu \mathrm{mol} / \mathrm{kg} /$ day. However, the present study demonstrates limitation that we used a fixed dose of NaHS without performing a dose-dependent study, thus may miss the potentially toxic or beneficial effects of NaHS.

In summary, improvement of endothelial function is involved in the antihypertensive mechanism of $\mathrm{H}_{2} \mathrm{~S}$. The protective effect of $\mathrm{H}_{2} \mathrm{~S}$ is attributable to, at least in part, suppression of vascular oxidative stress that involves inhibition of Ang II-AT $\mathrm{A}_{1} \mathrm{R}$ action, downregulation of NADPH oxidases, as well as upregulation of antioxidant enzyme SOD. $\mathrm{H}_{2} \mathrm{~S}$ may have therapeutic potential for renovascular hypertension.

\section{Conflict of Interest}

There is no conflict of interest.

\section{Acknowledgements}

This work was supported by National Natural Science Foundation of China (No.31171098), the Specialized Research Fund for the Doctoral Program of Higher Education of China (No.20121323110008) and the Natural Science Foundation of Hebei Province, China (No. C2013206080).

\section{Abbreviations}

ACh: acetylcholine; Ang II: angiotensin II; $\mathrm{AT}_{1} \mathrm{R}$ : angiotensin II type1 receptor; BCA: bicinchoninic acid; CBS: cystathionine $\beta$-synthase; CSE: cystathionine $\gamma$-lyase; CAT: cysteine aminotransferase; EDHF: endothelial-dependent hyperpolarized factor; EDRF: endothelial-dependent relaxing factor; HRP: horseradish peroxidase; $\mathrm{H}_{2} \mathrm{~S}$ : hydrogen sulfide; MDA: malondialdehyde; 3-MST: 3-mercaptopyruvate sulfurtransferase; NADPH: nicotinamide adenine dinucleotide phosphate; Phe: phenylephrine; ROS: reactive oxygen species; NaHS: sodium hydrosulfide; SNP: sodium nitroprusside; SHRs: spontaneously hypertensive rats; $\mathrm{O}_{2}{ }^{--}$: superoxide anion; SOD: superoxide dismutase; SBP: systolic blood pressure; TBST: tris-buffered saline; 2K1C: two-kidney, one-clip 


\section{References}

AHMAD FU, SATTAR MA, RATHORE HA, TAN YC, AKHTAR S, JIN OH, PEI YP, ABDULLAH NA, JOHNS EJ: Hydrogen sulphide and tempol treatments improve the blood pressure and renal excretory responses in spontaneously hypertensive rats. Ren Fail 36: 598-605, 2014.

AL-MAGABLEH MR, KEMP-HARPER BK, NG HH, MILLER AA, HART JL: Hydrogen sulfide protects endothelial nitric oxide function under conditions of acute oxidative stress in vitro. Naunyn Schmiedebergs Arch Pharmacol 387: 67-74, 2014.

BAYRAKTUTAN U: Free radicals, diabetes and endothelial dysfunction. Diabetes Obes Metab 4: 224-238, 2002.

BROWN DI, GRIENDLING KK: Nox proteins in signal transduction. Free Radic Biol Med 47: 1239-1253, 2009.

CAI H, HARRISON DG: Endothelial dysfunction in cardiovascular diseases: the role of oxidant stress. Circ Res 87: 840-844, 2000.

CALLERA GE, VARANDA WA, BENDHACK LM: Impaired relaxation to acetylcholine in 2K-1C hypertensive rat aortas involves changes in membrane hyperpolarization instead of an abnormal contribution of endothelial factors. Gen Pharmacol 34: 379-389, 2000.

CHEN ZF, ZHAO B, TANG XY, LI W, ZHU LL, TANG CS, DU JB, JIN HF: Hydrogen sulfide regulates vascular endoplasmic reticulum stress in apolipoprotein E knockout mice. Chin Med J (Engl) 124: 3460-3467, 2011.

CHOI S, KIM HI, SANG HP, MI JL, JUN JY, KIM HL, CHUNG JH, YEUM CH: Endothelium-dependent vasodilation by ferulic acid in aorta from chronic renal hypertensive rats. Kidney Res Clin Pract 31: 227-233, 2012.

DIJKHORST-OEI LT, STROES ES, KOOMANS HA, RABELINK TJ: Acute simultaneous stimulation of nitric oxide and oxygen radicals by angiotensin II in humans in vivo. J Cardiovasc Pharmacol 33: 420-424, 1999.

DOMBKOWSKI RA, RUSSELL MJ, OLSON KR: Hydrogen sulfide as an endogenous regulator of vascular smooth muscle tone in trout. Am J Physiol Regul Integr Comp Physiol 286: R678-R685, 2004.

DRUMMOND GR, SELEMIDIS S, GRIENDLING KK, SOBEY CG: Combating oxidative stress in vascular disease: NADPH oxidases as therapeutic targets. Nat Rev Drug Discov 10: 453-471, 2011.

FORD A, AL-MAGABLEH M, GASPARI TA, HART JL: Chronic NaHS treatment is vasoprotective in High-Fat-Fed ApoE(-/-) mice. Int J Vasc Med 2013: 915983, 2013.

HIGASHI Y, SASAKI S, NAKAGAWA K, MATSUURA H, OSHIMA T, CHAYAMA K: Endothelial function and oxidative stress in renovascular hypertension. $N$ Engl J Med 346: 1954-1962, 2002.

LI L, WHITEMAN M, GUAN YY, NEO KL, CHENG Y, LEE SW, ZHAO Y, BASKAR R, TAN CH, MOORE PK: Characterization of a novel, water-soluble hydrogen sulfide-releasing molecule (GYY4137): new insights into the biology of hydrogen sulfide. Circulation 117: 2351-2360, 2008.

LU M, LIU YH, GOH HS, WANG JJ, YONG QC, WANG R, BIAN JS: Hydrogen sulfide inhibits plasma renin activity. J Am Soc Nephrol 21: 993-1002, 2010.

MANCARDI D, PENNA C, MERLINO A, DEL SOLDATO P, WINK DA, PAGLIARO P: Physiological and pharmacological features of the novel gasotransmitter: hydrogen sulfide. Biochim Biophys Acta 1787: 864-872, 2009.

OLIVEIRA-SALES EB, NISHI EE, CARILLO BA, BOIM MA, DOLNIKOFF MS, BERGAMASCHI CT, CAMPOS RR: Oxidative stress in the sympathetic premotor neurons contributes to sympathetic activation in renovascular hypertension. Am J Hypertens 22: 484-492, 2009.

QU K, CHEN CP, HALLIWELL B, MOORE PK, WONG PT: Hydrogen sulfide is a mediator of cerebral ischemic damage. Stroke 37: 889-893, 2006.

SCHULZ E, GORI T, MUNZEL T: Oxidative stress and endothelial dysfunction in hypertension. Hypertens Res 34: 665-673, 2011.

SESHIAH PN, WEBER DS, ROCIC P, VALPPU L, TANIYAMA Y, GRIENDLING KK: Angiotensin II stimulation of NAD(P)H oxidase activity: upstream mediators. Circ Res 91: 406-413, 2002.

SHI YX, CHEN Y, ZHU YZ, HUANG GY, MOORE PK, HUANG SH, YAO T, ZHU YC: Chronic sodium hydrosulfide treatment decreases medial thickening of intramyocardial coronary arterioles, interstitial fibrosis, and ROS production in spontaneously hypertensive rats. Am J Physiol Heart Circ Physiol 293: H2093-H2100, 2007. 
TADDEI S, VIRDIS A, MATTEI P, SALVETTI A: Vasodilation to acetylcholine in primary and secondary forms of human hypertension. Hypertension 21: 929-933, 1993.

TAKAHASHI N, SMITHIES O: Human genetics, animal models and computer simulations for studying hypertension. Trends Genet 20: 136-145, 2004.

TANIZAWA K: Production of $\mathrm{H}_{2} \mathrm{~S}$ by 3-mercaptopyruvate sulphurtransferase. J Biochem 149: 357-359, 2011.

VANHOUTTE PM, SHIMOKAWA H, TANG EH, FELETOU M: Endothelial dysfunction and vascular disease. Acta Physiol (Oxf) 196: 193-222, 2009.

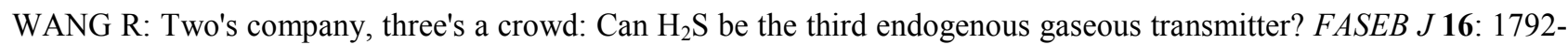
$1798,2002$.

WANG R: Hydrogen sulfide: a new EDRF. Kidney Int 76: 700-704, 2009.

WANG Y, ZHAO X, JIN H, WEI H, LI W, BU D, TANG X, REN Y, TANG C, DU J: Role of hydrogen sulfide in the development of atherosclerotic lesions in apolipoprotein E knockout mice. Arterioscler Thromb Vasc Biol 29: 173-179, 2009

YAN H, DU J, TANG C: The possible role of hydrogen sulfide on the pathogenesis of spontaneous hypertension in rats. Biochem Biophys Res Commun 313: 22-27, 2004.

YANG G, WU L, JIANG B, YANG W, QI J, CAO K, MENG Q, MUSTAFA AK, MU W, ZHANG S, SNYDER SH, WANG R: $\mathrm{H}_{2} \mathrm{~S}$ as a physiologic vasorelaxant: hypertension in mice with deletion of cystathionine gammalyase. Science 322: 587-590, 2008.

ZHAO W, ZHANG J, LU Y, WANG R: The vasorelaxant effect of $\mathrm{H}_{2} \mathrm{~S}$ as a novel endogenous gaseous $\mathrm{K}_{\text {ATP }}$ channel opener. EMBO J 20: 6008-6016, 2001.

ZHAO X, ZHANG LK, ZHANG CY, ZENG XJ, YAN H, JIN HF, TANG CS, DU JB: Regulatory effect of hydrogen sulfide on vascular collagen content in spontaneously hypertensive rats. Hypertens Res 31: 1619-1630, 2008. 